\title{
MESTIZAJE Y RACISMO EN LA REPRESENTACIÓN POLÍTICA EN MÉXICO
}

\author{
Kande Mutsaku Kamilamba*
}

RESUMEN: La ciudadanía apela a la integración social, la conciencia de pertenencia no sólo a una ciudad, un Estado nacional o un Estado federal, sino también a una comunidad soldada por una cultura y una historia. La ciudadanía no es la nacionalidad. Mientras la nacionalidad designa la pertenencia a un Estado-nación, la ciudadanía funda el derecho de participar, directa o indirectamente, en la gestión de la sociedad. La nacionalidad crea una solidaridad de los deberes, la ciudadanía da derechos. En América Latina y México la lógica homogeneizadora, heredada de la tendencia unificadora, ha tratado de eliminar y hacer desaparecer las diferencias en la región y con ello ha originado actitudes de discriminación hacia la población de origen africano, misma que se ha visto limitada en el ejercicio de la ciudadanía. Expresiones como ser blanco es una carrera; mulato, una maldición; negro, un saquito e'carbon que se le vende a cualquiera son muy elocuentes.

Palabras ClaVe: Mestizaje, Racismo, Ciudadanía, Afroméxico, Afroamérica, Discriminación.

ABSTRACT: Citizenship demands social integration and a conscience of belonging not only to a city, a national State or a federal State, but also to a community strengthened by its own culture and history. Citizenship it is not nationality. While nationality refers to a person belonging to a nationstate, citizenship is based on the right to participate, directly or indirectly, in society administration. Whereas nationality creates the duty of solidarity, citizenship grants the rights. In Latin America and Mexico, the homogenizer logic inherited from a unifying trend had tried to eliminate and make go away the differences of the region. As a result, discrimination attitudes have developed against African-origin people, whose citizenship's exercise has been constraint. Some expressions are revealing; for instance, "being white" ratifies you a place in society, "being mulato" is a curse, and "being black" means a little bag full of coal that can be sell to anyone.

Instituto Tecnológico y de Estudios Superiores de Monterrey, Campus Ciudad de México (kmutsaku@itesm.mx). 
KeYs WORDS: Mixed race, Racism, Citizenship, African Mexico, African America, Discrimination.

\section{EN TORNO AL MESTIZAJE}

Tradicionalmente el mestizaje se ha pensado como la mezcla de razas y culturas, sin embargo considero debe entenderse como la influencia de manifestaciones culturales y modos de concebir el mundo, cuya riqueza principal es la mezcla.

El gran mestizaje biológico fue una realidad desde los primeros años de la Conquista. Varias fueron las causas, pero un determinante se puede atribuir a la casi nula presencia de mujeres españolas y a la condición de sumisión de las indias. "España no rechazó la consanguinidad", desde 1503 “el gobernador Ovando recibió en Santo Domingo la instrucción real de procurar al casamiento de españoles con indios [...]."1

El arquetipo del mestizo, sin duda alguna, es el Inca Gracilazo de la Vega quien declara: "mestizo me llamo a boca llena". ${ }^{2}$ En él no sólo confluyen la sangre española y la sangre india, sino que se funden dos culturas distintas: la europea y la prehispánica. Su obra, reconocida tanto en los Andes como en la Península, anuncia una de las principales características de la ideología del mestizaje: la coexistencia "armónica" de dos mundos. Desde aquí advertimos el olvido o la negación de la raíz africana, presente desde los primeros momentos de la conquista en América.

Sin embargo, la exaltación de lo indio como origen, como pasado exclusivamente, evidencia una "preocupación" mayor: el indio vivo, considerado el elemento "bárbaro" de la nación, impedía el "acceso al progreso". ¿Cómo civilizar la barbarie? Las propuestas para llevar a cabo la creación de ciudadanos no fueron uniformes; en México, por

1 Agustín Basave Benítez, México mestizo. Análisis del nacionalismo mexicano en torno a la mestizafilia de Andrés Molina Enríquez, México, FCE, 1992, p. 17.

2 Alberto Flores Galindo, Buscando un inca: identidad y utopías en los Andes, La Habana, Casa de las Américas, 1986, p. 56. 
ejemplo, el liberal José María Luis Mora recomienda la inmigración europea, principalmente española, para acelerar el ritmo del mestizaje. En Argentina, Juan Bautista Alberdi propone una inmigración anglosajona como condición previa a la civilización.

No basta la integración política ni la social, también era necesaria una integración cultural total. Para lograrla había que crear, mediante el sistema educativo, una cultura homogénea capaz de borrar la heterogeneidad y así poder recurrir a una misma tradición, a lo propio, a lo específico en oposición a lo ajeno, a lo universal. Sin embargo, el proyecto de una nación homogénea se realiza tan sólo en el imaginario de su intelligentsia. La construcción de la nación, pese a todo, sigue siendo un proyecto inacabado.

\section{DE LA INVISIBILIDAD DE LO AFRO EN LA CULTURA MESTIZA}

Entender una realidad como la mestiza es tratar de dar razón a la vida humana, a la existencia del hombre, a las circunstancias que hacen la vida de éste. A mi parecer, la cultura adelanta a la política, a la historia militar y a los procesos económicos. Esta superposición no constituye un aspecto menos o desdeñable en todos los ámbitos empezando por la filosofía. Si la cultura puede predisponer a una sociedad a prepararse para la dominación ultramarina de otra, e incluso ser parte activa de tal dominación, también puede, al revés, contribuir a apaciguar o modificar tal disposición. Estos cambios no pueden darse sin la voluntad de hombres y mujeres de resistir las presiones del régimen colonial, de levantarse en armas, de desplegar ideas de liberación y de imaginar una nueva comunidad nacional capaz del salto final. Esto me lleva a decir que el respeto a la cultura no se da, se conquista.

En su desarrollo, las culturas latinoamericanas, en general, y la mexicana, en particular, tienen que tomar en cuenta la realidad cultural en su conjunto y totalidad y no partir desde la visión de los vencedores, ya que el punto débil de los vencidos ha sido y será siempre el no haber 
dejado sus memorias escritas. La escritura se convierte así en un elemento importantísimo para reconocer el papel del ser humano en la historia.

Es necesario que vayamos reescribiendo nuestra historia, pues la que tenemos ha sido escrita desde una perspectiva que puede ser contradicha por la realidad existencial cotidiana. Además urge acercarnos a la cultura mexicana desde una visión que abra el panorama a todas las culturas que estuvieron y están presentes en este país y no reducirnos sólo a lo español y lo indígena (visión de las mayorías y de la hegemonía).

El mestizaje es un fenómeno de unificación social que revela dos facetas que se patentizan en el siglo Xx: una, la hegemónica representada a través de la mezcla biológica y cultural, que ha servido como motivo para sentar las bases de un común denominador apto para los objetivos de la unificación nacional; la otra, cumple una función disimuladora al relegar a un segundo plano las diferencias étnico-regionales irreductibles y persistentes en el fondo de la imagen amalgamadora del símbolo racial nacional.

Con la idea del mestizaje se genera teóricamente un ideal de igualdad en la expresión sustencializadora del elemento racial, que transita así de lo biológico a lo espiritual (Molina Enríquez, Moisés Sáenz, José Vasconcelos, Manuel Gamio, etc.). El mestizaje viene a ser el correlato racial ideal pertinente al objetivo de lograr una unidad nacional concreta y es significativo que el prototipo de la integración nacional se conciba como tal, es decir, como racial. En efecto, el mestizaje viene a ser como bien lo afirma Kurnitzky, ${ }^{3}$ el símbolo de una utopía social: la de la mezcla de razas que supera al racismo. Sin embargo, en el interés por llevar a cabo la consumación del mestizaje, prevalece el principio de una intención purista en la que sigue predominando la convicción de la hermandad de sangre como fundamento primigenio de la nación.

En la mayoría de los países latinoamericanos y en México, en particular, este mestizaje no ha modificado la base del paradigma primiti-

3 Kurnitzky, "Mestizaje y utopía", La Jornada Semanal, núm. 146, México, 29 de marzo, 1992. 
vo de la relación sangre-pureza raza-nación, pero ha cambiado el significado de sus términos, al transformar lo negativo en positivo y al olvidar otros componentes que incomodaban en el momento.

Los aspectos homogeneizadores del mestizaje tienden a escamotear diferencias socioculturales marcadas, existentes en el plano regional, como las que se encuentran entre los indígenas, los así llamados "morenos" y los mestizos, de manera que una diferenciación pervive de modo subyacente a una tendencia integracionista facilitadora y promovida por defensores del Estado-nación.

El mestizaje pasa necesariamente por la dialéctica de la aculturación y esta última por las relaciones sociales interraciales, por una parte, e intrarraciales, por otra, pues los indígenas, hispanos y africanos (negros) estuvieron relativamente relacionados entre sí, aunque de manera asimétrica. Estos fenómenos de aculturación tuvieron diferente intensidad según el estatus de los hispanos respecto de los indígenas y de los africanos y sus descendientes. La aculturación de estos dos últimos no siguió un camino único, especialmente porque las situaciones individuales fueron muy diversas y porque las relaciones entre cada grupo racial tuvieron alternativas y obedecieron a estrategias diversas.

En la reconstrucción de los procesos históricos nacionales de México se ha privilegiado a los elementos hispánicos e indígenas, asumiendo de manera casi natural la completa asimilación, entendida más como desaparición que como contribución de los elementos de origen africano. Una revalorización de la contribución africana en todo lo relacionado con la construcción de la nación mexicana, lo que vale decir de todas las naciones americanas, desde nuestro punto de vista, exige una relectura de la historia centrada en la investigación del proceso de integración y, sobre todo, de los mecanismos con los cuales ésta se llevó a cabo. A mi parecer, hay proyecciones que impiden ver con claridad el proceso de integración de esta población en las culturas nacionales americanas en general y mexicana en particular. Dos de ellas son: la ideología nacional relacionada al origen dual de las identidades, muy fuerte en el caso de México: es decir el indígena y el hispánico. Y la costumbre de bus- 
car influencias y contribuciones sociales y culturales solamente ahí donde existe o existió una presencia física del grupo humano con el que éstas son relacionadas, lo que ha llevado y lleva a la idea generalizada de que la contribución africana, en algunos países americanos como México, Argentina, Uruguay, poco menos que desapareció en el momento en que los censos y demás textos legales dejaron de mencionarla como grupo racial o casta, o bien que éste sólo se encuentra todavía ahí donde existen rasgos físicos relacionados a la población de origen africano como es el caso de Brasil, Colombia, Cuba, etcétera.

La lectura que el mexicano ha hecho de su historia, y la manera como se ha entendido y ha formado su "nosotros" ha sido excluyente y ha dejado fuera del juego a un actor social importante que es el negro. Al mexicano se le ha olvidado que el negro fue el primero que le enseñó el camino a la libertad cuando en 1604, Yanga y Francisco de la Mattosa se rebelaron en contra del poder virreinal. Además de tener en su historia y lucha por la Independencia a personajes mulatos de la talla de José María Morelos y Pavón, Juan Álvarez y Vicente Guerrero. Este hecho se evidencia en la manera de acercarse al mestizaje donde podemos enfatizar el aspecto del olvido, para no decir negación del aporte africano a este "nosotros".

Durante tres siglos las culturas africanas fueron vertidas por fuerza, a través de más de doce millones de seres humanos convertidos en motores de sangre en las culturas americanas. Los esclavos africanos, aun reducidos a manos y pies de sus señores, tuvieron la oportunidad de vivir en estas tierras americanas y de dar una respuesta positiva o negativa a la nueva realidad o a la nueva situación donde se encontraron. Las preguntas acerca de la vida, de la realidad y las respuestas dadas desde una cierta situación serían los elementos constitutivos de esta cultura que se llamaría afroamericana. De este modo y para hacer justicia a la historia, podemos afirmar que lo afroamericano es una de las figuras específicas que forma parte de la cultura global americana.

La situación de los pueblos afromexicanos no está determinada únicamente por esta presencia, sino en mayor grado por el desarrollo eco- 
nómico y social de las sociedades que habitan este país. Con su sudor, los africanos traídos a América contribuyeron, colaboraron e hicieron posible el desarrollo del capitalismo en esta parte del mundo. Además, la amplia distribución y diversidad de los pueblos africanos y su contribución cultural y estética a la riqueza de las tradiciones de América constituyen el producto final de largos siglos de cambio, durante los cuales los afroamericanos no fueron simplemente sujetos pasivos e inconscientes de procesos externos sino, por el contrario, agentes activos de las propias transformaciones. Por razones ideológicas se ha olvidado en algunos países y negado en otros, caso de México, de incorporar lo afro a lo americano en general y lo mexicano en particular. "Olvido que —al decir de Bilbao- es causa de nuestros errores. Olvido que está condicionado o causado por la posición social, ya que se trata de una cuestión de mesa, de albergue, de renta". ${ }^{4}$ Esto ha llevado al desconocimiento del otro, y del otro africano.

Desde la llegada de los occidentales a este continente hasta la actualidad, algunos países americanos como México han estado orientados hacia la asimilación de los valores de la cultura occidental, pero por otra parte, la búsqueda de la identidad de las poblaciones mestizas, es, hoy día, un propósito vital. La historia es, en estos últimos tiempos, la de las dificultades o logros para consolidar un proyecto de cultura nacional que tome en cuenta lo multiétnico y lo pluricultural del país. Para esto, se necesita una relectura de la historia que vuelva a dar a cada grupo su valor real, lectura hecha desde la base de la pirámide y no desde una visión elitista. La afirmación del patrimonio colectivo, el dar reconocimiento a otras nociones que se derivan de ella, como la cultura popular, la incorporación de la parte afro a lo mexicano darán razón del mestizaje y harán más comprensible éste como proceso global que produjo una multitud de bienes culturales como las lenguas criollas, caso del vocablo como chingar, tradiciones orales, religiones sincréticas, música, bailes, etcétera.

${ }^{4}$ Bilbao citado por Arturo Andrés Roig, Teoría y crítica del pensamiento latinoamericano, México, FCE, 1981, p. 33. 
Con ello no se está señalando una división en la que quedarían por un lado lo africano, lo indígena y lo europeo. Lo mexicano es en realidad la fusión de lo indígena, lo europeo, lo africano y mucho más. No se trata de proclamar la autonomía de cada cultura, pues por particular que parezca es inseparable del campo cultural global en el cual y en relación con el cual se configura y se desarrolla de manera particular y original. La historia nos enseña que desde el momento en que el europeo entra en contacto con el autóctono de América estaba presente también el africano. No es posible querer borrar de un plumazo todo un legado histórico que la realidad revela diariamente. Aunque fuera o se considerara éste "vergonzoso", forma parte de la identidad mexicana y debe ser tomado en cuenta en la definición de lo que hoy se conoce como la mexicanidad.

Los movimientos culturales de estos últimos tiempos en América han inducido a los americanos a asumir todas sus tradiciones, pues a medida que conocemos más nuestra identidad somos, a un tiempo, más específicos y más universales. Aunque parecería que esta búsqueda se ha confiado sólo en manos de los antropólogos e historiadores y parecería que los sociólogos y los filósofos no se sienten tocados por esta necesidad.

En esta vivencia concreta, el mexicano no puede seguir cerrando los ojos a la presencia física y cultural del aporte africano. En México, como en muchos otros países del continente, no hay que buscar el aporte africano como si fuera algo aparte, algo que se tiene que haber guardado de manera intacta, sino como elemento que es parte del acervo cultural mexicano. De ahí que se insista en que toda forma de cultura o al decir de algunos "subcultura", se inscriba en un sistema de intercambio en el que se efectúan las relaciones de integración, influencias, oposiciones y resistencia.

¿Hasta cuándo seguirá esta negación o este olvido? ¿Hasta cuándo la ciencia en este país seguirá siendo presa de la política, la economía y cómplice de la alienación? 


\section{EN TORNO AL CONCEPTO CLAVE: CIUDADANO}

La revisión teórico-histórica del concepto del ciudadano nos ayuda a identificar las contradicciones actuales entre la semántica del término y la realidad política de una sociedad caracterizada por la desigualdad social y la composición multiétnica y multicultural.

El concepto del ciudadano está profundamente enraizado en la tradición occidental moderna, lo cual dificulta su incorporación a la identidad de las comunidades étnica y culturalmente distantes de la modernidad. El concepto de ciudadano, que surge como efecto de la Revolución francesa y el desarrollo de la sociedad industrial, tiene dos acepciones: ${ }^{5}$ la civil, que concibe a los ciudadanos como sujetos de la misma ley; y la étnica, que lo concibe como miembro de una comunidad nacional. La primera acepción, la civil, se remonta a la concepción de la igualdad y libertad civil de John Lock y al pensamiento liberal clásico. La segunda acepción, la étnica fue moldeada por el pensamiento republicano, que considera el ámbito político (la ciudadanía) como el espacio por excelencia de la libertad individual, y postula que el individuo debe ser ciudadano antes que individuo. Adicionalmente, el republicanismo identificó el aspecto étnico con el postulado de la unidad nacional, que ignoraba las diferencias culturales o étnicas de los Estados-nación, y esperaba una aculturación al modelo nacional predominante, como etapa indispensable de la modernidad.

La tercera fuente fundamental para el concepto moderno del ciudadano es la obra de T. H. Marshall, Ciudadanía y clase social, publicada en los años cincuenta, y que se constituyó como fundamento teórico del Estado de bienestar europeo. T. H. Marshall añade al concepto del ciudadano el aspecto social: considera que la ciudadanía implica la inclusión del individuo a la herencia social de una comunidad, y el derecho de compartir los estándares de vida con el resto de la sociedad. Marshall

5 Isaac Jeffrey C., "The meanings of 1989", Social Research, vol. 63, núm. 2, Nueva York, verano, 1996. 
enriquece el concepto de ciudadanía con el postulado de una especie de igualdad básica, que no excluye la existencia de clases sociales, pero sí obliga al Estado a incluir a todos los ciudadanos no solamente en la igualdad política, sino también social.

La acepción republicana de la ciudadanía, muy enraizada en las sociedades que han pasado por los procesos revolucionarios - como Francia y México - al postular la unidad nacional, no solamente margina las identidades locales, particulares o étnicas, sino que las estigmatiza como la fuente del conflicto y la expresión de fuerzas atávicas, premodernas de la sociedad. Adicionalmente, el republicanismo influyó en que la conceptualización de Marshall de la ciudadanía social fuera condicionada a la aceptación del proyecto nacional predominante, y que cualquier proyecto alternativo no solamente fuera visto como atentado a la unión nacional, sino también al desarrollo. De ahí que en muchos países con población heterogénea, como México, el concepto del ciudadano significó la exclusión para los grupos étnicos y culturales minoritarios.

La ciudadanía apela a la integración social, la conciencia de pertenencia no sólo a una ciudad, un Estado nacional o un Estado federal, sino también a una comunidad soldada por una cultura y una historia en el interior de fronteras más allá de las cuales velan enemigos, competidores o aliados, y esta conciencia puede oponerse al universalismo de los derechos del hombre. ${ }^{6}$

El fin del siglo $\mathrm{xx}$ atestigua un renacimiento de las identidades étnicas y culturales, del cual México también es protagonista. De ahí surge la necesidad de redefinir el concepto, para que la ciudadanía no excluya proyectos particulares del proyecto nacional. Las instituciones políticas modernas deben de aceptar un concepto ampliado de ciudadanía, promoverlo entre los grupos marginados, para que a su vez éstos se identifiquen con el Estado. Como lo plantea Touraine, el reto es lograr

${ }^{6}$ Alain Touraine, ¿Qué es la democracia?, Buenos Aires, FCE, 1999, p. 45. 
el equilibrio entre la identidad comunitaria y la nacional, porque sólo la nacional permite crear una comunidad democrática y asegurar el interés por las elecciones nacionales. Si no sucede esto, tenemos la huida hacia la comunidad, los problemas personales, ignorancia de problemas nacionales, desprecio o desinterés por instituciones nacionales.

La ciudadanía no es la nacionalidad, aunque en ciertos países estas nociones son jurídicamente indiscernibles: la segunda designa la pertenencia a un Estado nación, mientras que la primera funda el derecho de participar, directa o indirectamente, en la gestión de la sociedad. La nacionalidad crea una solidaridad de los deberes, la ciudadanía da derechos. ${ }^{7}$

La Constitución mexicana, después de casi dos siglos de vida nacional, reconoce legalmente la existencia de los pueblos indígenas modificando su artículo cuarto. El reconocimiento de la composición pluricultural, multiétnica y multilingüística es un hecho de innegable relevancia en México para redefinir la condición demográficamente "minoritaria". También lo es para establecer las bases de una democracia. Sin embargo, este reconocimiento constitucional no se ha traducido en un concepto de ciudadanía capaz de incluir a los grupos minoritarios. Entre el derecho constitucional y las prácticas sociales median ideologías e identidades excluyentes fuertemente arraigadas en el pensamiento de las élites en el poder en México. En la mayoría de las regiones del país, la igualdad constitucional no asegura la promoción de los derechos colectivos $\mathrm{y}$, en cambio, persisten diversas formas de exclusión que contradicen el espíritu de tolerancia y respeto contenidos en la carta magna de México.

El discurso dominante, construido según y desde los ideales del universalismo monocultural, reivindica la diversidad étnico-racial de la nación. Sin embargo, las políticas hacia las minorías que siguen bajo la tutela de las instituciones del Estado, no han logrado sentar las bases para transformar el carácter conflictivo y lograr las soluciones de largo plazo para superar las relaciones entre Estado, etnia y nación. Entre el dis-

${ }^{7}$ Ibid., p. 104. 
curso y práctica no hay una relación mecánica. $\mathrm{Ni} \mathrm{el} \mathrm{reconocimiento} \mathrm{de}$ la diversidad se expresa siempre en acciones, ni éstas son congruentes con las ideas contenidas en los nuevos discursos de la multiculturalidad. El respeto a la diferencia de las minorías en México ha quedado atrapado en discursos que aceptan solamente símbolos y prácticas compatibles con las instituciones nacionales y no ponen en contradicho la soberanía y unidad nacional.

En este contexto, como bien lo dice Maurice Merleau Ponty ${ }^{8}$ los que tienen el poder se adjudican la capacidad y autoridad de defender al Estado y el monopolio del interés nacional, los recursos, la identidad, la unidad y la soberanía nacional. Es entonces cuando las ideologías racistas y discriminatorias pueden encontrar la legitimidad y las condiciones para su difusión basadas en la amenaza del Otro diferente.

A pesar de los esfuerzos que el gobierno mexicano ha realizado, siguen prevaleciendo formas discriminatorias, y aunque éstas no se quieran mirar como tales y se les quiera ver como un fenómeno del pasado colonial o, en el mejor de los casos, se les califiquen de inofensivas, y a veces de irrelevantes en comparación con las contradicciones, divisiones y prejuicios de clase que dividen a la sociedad mexicana, lo cierto es que siguen siendo un problema latente en nuestros días.

Parafraseando a María Dolores París Pombo ${ }^{9}$ podemos afirmar que la negación de la diversidad étnica y racial, propuesta en nombre de la igualdad de todos los ciudadanos, sin la distinción de la afirmación de lo particular y de la diferencia del Otro en situación de desigualdad, fue la base a partir de la cual se legitimaron las relaciones de explotación y dominación tanto en México como en América Latina.

8 Maurice Merleau Ponty, Fenomenología de la percepción, trad. Jem Cabanes, Barcelona, Península, 1975, aplicado a la realidad latinoamericana por Horacio Cerutti Guldberg en su libro Presagio y tópica del descubrimiento, México, CCyDEL-UnAM, 1991 (Col. 500 años después, 4).

9 María Dolores París Pombo, Identidades colectivas de las élites en el centro de Chiapas (1971-1993): Tuxtla Gutiérrez y San Cristóbal de Las Casas, México, 1997 (tesis de doctorado, FLACSO). 
La supuesta incompatibilidad entre culturas y la naturalización de las diferencias físicas y sociales han estado vigentes en las relaciones interétnicas y han conducido al rechazo absoluto del Otro, hoy considerado en su propia tierra como minoría. Este hecho mina la posibilidad de desarrollar en México una verdadera democracia.

Uno de los grandes cambios que caracterizan a México es el predominio de la democracia electoral. Sin embargo, México está consumando la transición en medio de la crisis que vive la democracia electoral. El pensamiento occidental conceptualizó la democracia representativa con el presupuesto de un ciudadano educado, que se mantiene al tanto de los problemas de la sociedad y, en general, está interesado en la vida pública. El problema es que en la realidad, este público ciudadano no existe como tal. Tanto los individuos como las comunidades perciben los intereses del Estado o de la nación como divorciados de la realidad que ellos están viviendo. Por otro lado, no ven los resultados de la acción estatal en sus comunidades. La consecuencia es la pérdida de interés en los mecanismos electorales, como una de las formas de lograr el mejoramiento de la vida en la comunidad.

Un público democrático efectivo sería aquel en el que los ciudadanos sintieran el efecto de las acciones de gobierno, entendieran la relación de las políticas con esos efectos, discutieran la relación entre los fines y los medios y que, a través de los arreglos democráticos, se conectaran con un Estado que respeta su voluntad. Tal era la idea. Pero [...] son precisamente esas instituciones políticas y sociales las que impiden a los ciudadanos organizarse de manera activa y, de ese modo, la gobernabilidad se zafa de su atadura democrática. Las esferas del Estado y la sociedad habían perdido vínculos. Las reflexiones de Dewey sobre los síntomas de esta disyunción suenan perturbadoramente familiares al oído contemporáneo: bajos niveles de votación, desconfianza en el gobierno y un sentido cínico de que todo el aparato político es una suerte de disfraz que esconde el hecho de que, en todo caso, los grandes negocios mangonean al gobierno. ${ }^{10}$

10 Archon Fung, "Esferas de deliberación: gobernar después del centralismo democrático", Metapolítica, vol. 4, núm. 14, México, abril-junio, 2000, pp. 88-109. 
Hablar de la democracia implica considerar espacios sociales y políticos. Las fronteras de la democracia van más allá de quién gobierna, implica considerar el cómo se gobierna y la forma cómo la ciudadanía asume y vive dicho gobierno. El ciudadano es entonces el protagonista de la democracia, es quien toma parte en la vida pública bajo el marco normativo imperante en el país.

Se consideran ciudadanos mexicanos todos los hombres y mujeres que cumplen con lo estipulado en el artículo 34 de la Constitución Política de los Estados Unidos Mexicanos que a la letra dice: "Son ciudadanos de la República los varones y mujeres que, teniendo la calidad de mexicanos, reúnan, además, los siguientes requisitos: haber cumplido 18 años y tener un modo honesto de vivir". Asimismo, se establece que los ciudadanos mexicanos, independientemente del grupo social al que pertenezcan - pues recordemos que constitucionalmente, en el artículo $4^{\circ}$ se reconoce que la nación mexicana tiene una composición pluriculturalson iguales y tienen los mismos derechos y obligaciones ante la ley.

No obstante a pesar de los esfuerzos siguen existiendo zonas en nuestro país donde aún falta mucho por hacer en materia de formación y orientación ciudadana, sobre todo en aquellos lugares donde la diversidad de grupos sociales es más amplia y, por tanto, es más difícil transmitir de manera homogénea y eficiente los mensajes a la población; es necesario considerar que cada uno de esos grupos tiene sus propios valores, costumbres, necesidades y convicciones, todos ellos acordes a una realidad política, económica y cultural determinada.

Asimismo, se estudiará aquel lugar así caracterizado porque cuenta con una población integrada por grupos de personas con condiciones culturales y raíces ideológicas que son consideradas vulnerables en comparación con aquellas personas que viven en urbes y tienen una condición socioeconómica distinta; dichos grupos, también conocidos como indígenas o grupos étnicos, representan $10 \%$ de la población nacional, y se encuentran aglutinados en 56 grupos étnicos, según datos del Instituto Nacional de Estadística, Geografía e Informática (INEGI), determinados a partir de los diferentes tipos de lengua que se hablan en México. 
De ahí entonces que no se reconozca la existencia de otros grupos de población, a parte de los indígenas, como los grupos de personas negras, mejor conocidas como mulatas o afromestizas, aun cuando no se conoce con precisión a cuántos ascienden, pues son hablantes de español y por tanto no hay manera de distinguirlos al momento de aplicar los censos de población que se realizan cada 10 años en México.

La marginación es un dato que expone una realidad precaria en muchos ámbitos, no sólo en el económico —el cual más bien funge como el origen de otros rezagos sociales, como la falta de educación, salud y vivienda - sino políticos, como la desconfianza institucional e inseguridad pública, altos índices de delincuencia, entre otros.

La marginación y la pobreza, junto con todas sus implicaciones, se imponen en Guerrero como un problema generalizado, como una forma de vida donde la inestabilidad, la inseguridad, la desconfianza y la apatía por participar en la vida política resulta ser hoy en día la gran constante. Es importante señalar que precisamente la zona sureste del estado es donde se encuentra una mayor cantidad de grupos indígenas hablantes de tlapaneco, amuzgo, náhuatl y mixteco, entre otros, pero también una fuerte presencia de la población de origen africano llamados afromexicanos.

\section{Sólo QuiEn ES NEGRo SABE LO QUE SIGNIFICA SER NEGRO EN MÉXICO}

El color es un accidente cruel que separa a las personas en el mundo; tal vez el más cruel de los accidentes, porque, aun siendo tan pequeño —en sí mismo y en lo que significa一, abre sin embargo un gran abismo. Es un accidente complicado por los mitos raciales y por la incomprensión de diferencias económicas, políticas y espirituales. Ha levantado un muro alrededor de hombres y de naciones, $\mathrm{y}$ tras de ese muro han surgido los mitos de superioridad. Como son tan invasores, los mitos van entremezclándose con las realidades y hay hombres que se mantienen atrincherados tras un muro, en lugar de salir y ponerse en contacto con los hombres del otro lado. Thomas Patrick Melady en The Revolucion 
of Color dice: "Ser blanco es una carrera, mulato, una maldición, negro un saquito e'carbon que se le vende a cualquiera".

Como decía F. Fanón: "Cuando me aman me dicen que es a pesar de mi color. Cuando me detestan, agregan que es por mi color. Aquí o allá estoy prisionero del círculo infernal". Todos los hombres, todos nosotros anhelamos especificidad, pero también nos gusta escabullirnos en ella. Queremos ser una cosa, pero ya no esta cosa o de nuevo aquella otra. Tememos no ser nada y fantaseamos con serlo todo, pero no advertimos que todo es una versión agitada. Un bravo a la identidad, pues: impone disciplina.

Hoy en día, la tendencia de todos en el nivel económico, político y social va hacia la homogeneización, en lo político conocido como ciudadanización. Por eso en algunos países se toman en cuenta las diferencias culturales ya que son países que, aun siendo diferentes, se respetan en lo cultural. No hay uno solo que se crea superior a los demás, y aunque lo haya, no se impone sobre los demás. La globalización ha propiciado, a pesar de sus fuerzas hegemónicas, una primavera identitaria desbordante que no puede ser descalificada por algunos excesos de añejos fundamentalismos políticos y religiosos. Pero en el Tercer Mundo, donde se aplica la misma propuesta económica y política, y hasta social, no se toman en cuenta las diferencias culturales. Ya no se piensa en términos de identidades culturales sino de Identidad Nacional y de ciudadano. Es evidente que no podemos abogar por una supuesta pureza cultural o de identidad. Actualmente lo que nos hace falta es aceptar al otro como diferente. Creemos que la homogeneización y la globalización son considerados como vías de integración por excelencia, y pretendemos implantarlas, sin que nos importe la destrucción de las otras culturas. La homogeneización no hace justicia a las diferencias. Ante esto es conveniente promover la idea de la unidad en la diversidad, ver las diferencias no como obstáculo sino como riqueza y algo positivo para la realización del hombre aquí y ahora.

El gran problema de la defensa de una única identidad es que deriva en un racismo en el que las diferencias se plantean en claves de su- 
perioridad e inferioridad. Y como hay una cultura que se considera superior a las otras, las inferiores deben asimilarse o incorporarse a la superior. El no hacerlo desata los mecanismos de exclusión porque el que no se adapta a este modelo es atrasado y no entra en la modernidad... pero si uno lo hace deja de ser uno mismo, se aliena y termina por ser excluido también porque al fin y al cabo no se sabrá quién es. En nombre de una supuesta identidad colectiva se reproducen prácticas de intolerancia que matan la riqueza de la humanidad que reside en las diferencias, en la diversidad, en la multiplicidad, en la unidad.

El racismo, realidad que ya es parte de la experiencia existencial del negro o de todo negro, necesita una atención particular de parte de estos sujetos históricos relegados al segundo plano y considerados a veces como no humanos por el europeo, que se considera a sí mismo modelo de humanidad por excelencia. Si el negro no trabaja en este punto no saldrá de esta casilla, donde la historia oficial de los países desarrollados lo han puesto y será siempre tratado con base en la forma como ha sido presentado al mundo, o sea como un ser servil, un esclavo.

El factor discriminatorio del sistema económico hizo que el acceso de la comunidad negra al ámbito intelectual, religioso y social haya sido siempre insignificante y periférico. Dentro de la lógica de los sistemas opresores no hay espacio geográfico, social, político y cultural para que el negro pueda tomar una decisión a partir de su contexto vital en el continente. Por otro lado, desde la perspectiva del negro oprimido, es posible observar cómo su sangre y sudor refuerzan la sociedad y el mundo económico actuales. Igual importancia dan los negros al estudio del problema del racismo en los contextos escolares y literarios en los que se perpetúan sistemáticamente los mitos y estereotipos racistas que estigmatizan al negro, su cultura y valores, a la vez que idealizan determinadas formas de vida típicas de la sociedad de consumo. La trascendencia de esos textos tiene que ver con la necesidad de combatir la introyección de valores racistas por parte de los niños negros, hecho que se da en su propio detrimento, $\mathrm{y}$ de crear una visión alternativa, una autoimagen positiva desde la misma comunidad negra. Se quiere erradicar el racismo 
o la discriminación racial que se presenta bajo diferentes formas concretas como las restricciones a la movilidad, al derecho a establecerse libremente en cualquier lugar del territorio nacional, y la segregación racial por lo que respecta a puestos, fuentes de créditos, educación y otros. Dentro de estos otros, uno llama mi atención: es el campo de los medios de comunicación masiva. De hecho la prensa, la radio y la televisión no sólo reproducen valores francamente racistas en sus editoriales, comentarios y espacios humorísticos, sino que no dedican ningún espacio para destacar los aportes positivos del negro al desarrollo económico y cultural del país, ni para dar a conocer sus valores culturales al resto de la población. Y cuando se logra algo positivo, esto es presentado más en el tono folclórico al que le falta seriedad. Se burlan en lugar de valorarlo.

En los últimos años han surgido en América Latina, en general, y en México, en particular, un esfuerzo por valorar la cultura negra. Estos esfuerzos se proponen rescatar y reinterpretar los valores tradicionales y las creencias artísticas (literatura, pintura, tradición oral, música...) así como el conocimiento popular (medicina, alimentación...) y dar un estatus justo a las lenguas criollas. Toda esta labor es producto del trabajo de los mismos negros, salvo el caso de México, donde éstos luchan no por lograr el reconocimiento y la incorporación de su cultura como una dimensión de la cultura nacional, regional, sino por sobrevivir, ya que en el imaginario nacional son inexistentes al ser incorporados al genérico apelativo de mexicanos. Dentro de esa perspectiva hay también claros esfuerzos por reinterpretar a los clásicos afrolatinoamericanos recuperando la parte africana en ellos, como es el caso de Simón Bolívar que reconocía como su madre a la negra que le amamantó, y en el caso de México ir recuperando, como ya lo hemos mencionado, a los personajes mulatos que han sido piezas fundamentales en la formación de este país como lo fueron José María Morelos y Pavón, Juan Álvarez, Vicente Guerrero... 
BIBLIOGRAFÍA

Basave Benítez, Agustín, México mestizo: análisis del nacionalismo mexicano en torno a la mestizofilia de Andrés Molinas Enríquez, México, FCE, 1992.

Flores Galindo, Alberto, Buscando un inca: identidad y utopía en los Andes, La Habana, Casa de las Américas, 1986.

FAnÓn, Frantz, Los Condenados de la tierra, prefacio de Jean Paul Sartre, trad. Julieta Campos, México, FCE, 1963.

KuRnitzky, "Mestizaje y utopía”, La Jornada Semanal, núm. 146, México, 29 de marzo, 1992.

RoIG, ARTURO ANDRÉS, Teoría y crítica del pensamiento latinoamericano, México, FCE, 1981.

IsAaC, JeFFrey C., "The meanings of 1989", Social Research, vol. 63, núm. 2, Nueva York, verano, 1996.

Touraine, Alain, ¿Qué es la democracia?, Buenos Aires, FCE, 1999.

Merleau Ponty, Maurice, Fenomenología de la percepción, trad. Jem Cabanes, Barcelona, Península, 1975, aplicado a la realidad latinoamericana por Horacio Cerutti Guldberg en su libro Presagio y tópica del descubrimiento, México, CCyDEL-UNAM, 1991 (Col. 500 años después, 4).

París Pombo, María Dolores, Identidades colectivas de las élites en el centro de Chiapas (1971-1993): Tuxtla Gutiérrez y San Cristóbal de Las Casas, México, 1997 (tesis de doctorado, FLACSO).

ARCHON FunG, "Esferas de deliberación: gobernar después del centralismo democrático", Metapolítica, vol. 4, núm. 14, México, abriljunio, 2000.

Hurbon Laennec, Le barbare imaginaire, Haití, Henri Deschamps, 1987.

Rodney Walter, Cómo Europa subdesarrolló al África, México, Siglo XXI, 1982. 
